\title{
Does the GMC think it's immune to its own guidance regarding candour?
}

\author{
Christoph Lees clinical reader in obstetrics
}

Imperial College London, London, UK

Dean has established the true degree of independence and transparency of the GMC's Greenaway report. ${ }^{1}$ That this hasn't sent shock waves through the medical establishment attests to the nature of the relations between the GMC, the Department of Health, and medical education quangos. Dean's findings may reflect a pattern of behaviour at the GMC that does not favour candour.

The recent report on deaths of doctors while under investigation, commissioned by the GMC, was in fact an internal review, despite the GMC calling it "independent." Similarly, in March the GMC press released a study with the headline: "New research finds that GMC decisions are fair to doctors under investigation." ${ }^{3}$ The research was billed as independent yet commissioned and paid for by the GMC. The report examined how GMC processes were followed by interviewing GMC fitness to practise staff but not any doctors under investigation. How can the report conclude that GMC decisions are fair to doctors?

Another GMC press release said that a major consultation by the GMC had "found strong support for proposals to deal with the small number of doctors who put patients at significant risk or cause them harm." ${ }^{\prime 4}$ Serious concerns were raised about the process, which the GMC has not acknowledged. ${ }^{5}$ The consultation required doctors to identify themselves, which is hardly likely to encourage critical responses from a profession already suspicious of their regulator. Approximately $0.1 \%$ of registered medical practitioners responded, and the BMA's response was negative in many questions posed. So how the GMC can claim "strong support" is a mystery.
The duty of candour requires doctors to tell the whole truth and not leave out important salient facts-in short, not to mislead. One would arguably expect the regulator to hold itself to a stricter standard of conduct with the press and public. Section 72 of Good Medical Practice (2013) states, "You must make sure that any evidence you give or documents you write or sign are not false or misleading. (a) You must take reasonable steps to check the information. (b) You must not deliberately leave out relevant information."

Maybe the GMC sees itself immune to its own guidance regarding candour. But if it doesn't set an example, how can it expect its registrants to take its guidance seriously?

\section{Competing interests: None declared.}

Full response at: www.bmj.com/content/350/bmj.h2400/rr-5.

1 Dean BJF. GMC's supposedly independent training review included secret meetings with politicians. BMJ 2015;350:h2400. (7 May.)

2 Horsfall S. Doctors who commit suicide while under GMC fitness to practise investigation. Internal review. Dec 2014. www.gmc-uk.org/Internal_review_into_suicide_in_FTP_ processes.pdf 59088696.pdf.

3 General Medical Council. New research finds that GMC decisions are fair to doctors under investigation. Press release. 13 Mar 2015. www.gmc-uk.org/news/26346.asp.

4 General Medical Council. Strong support for proposals to improve patient protection and public confidence in doctors. Press release. 25 Feb 2015. www.gmc-uk.org/news/26294. asp.

5 Jalmbrant M. The GMC consultation on regulation suggests the regulator has ambitions to be a punitive body based on "maintaining public confidence," whilst the proposed regulatory changes may harm doctors and patient care. [Electronic response to Walshe K, Archer J. Medical regulation: more reforms are needed.] BMJ 2014. www.bmj.com/ content/349/bmj.g5744/rr/771934. 